\title{
In-Hospital Mortality in Patients with Idiopathic Pulmonary Fibrosis: A US Cohort Study
}

\author{
Michael T. Durheim ${ }^{1,2,3}$ (D) Jennifer Judy ${ }^{4} \cdot$ Shaun Bender $^{5} \cdot$ Dorothy Baumer $^{4} \cdot$ Joseph Lucas $^{6} \cdot$ Scott B. Robinson ${ }^{4}$. \\ Omar Mohamedaly ${ }^{1} \cdot$ Bimal R. Shah ${ }^{2} \cdot$ Thomas Leonard $^{5}$. Craig S. Conoscenti ${ }^{5} \cdot$ Scott M. Palmer ${ }^{1,2}$
}

Received: 19 March 2019 / Accepted: 4 September 2019 / Published online: 20 September 2019

(c) The Author(s) 2019

\begin{abstract}
Purpose In patients with idiopathic pulmonary fibrosis (IPF), hospitalizations are associated with high mortality. We sought to determine in-hospital mortality rates and factors associated with in-hospital mortality in patients with IPF.

Methods Patients with IPF were identified from the Premier Healthcare Database, a representative administrative dataset that includes $>20 \%$ of hospital discharges in the US, using an algorithm based on diagnostic codes and billing data. We used logistic regression to analyze associations between patient-, hospital-, and treatment-related characteristics and a composite primary outcome of death during the index visit, lung transplant during the index visit and $>1$ day after admission, or death during a readmission within 90 days.

Results The cohort comprised 6665 patients with IPF hospitalized between October 2011 and October 2014. A total of $963(14.4 \%)$ met the primary outcome. Factors significantly associated with a higher risk of the primary outcome included mechanical ventilation [odds ratio 4.65 (95\% CI 3.73, 5.80)], admission to the intensive care unit [1.83 (1.52, 2.21)], treatment with opioids $(3.06[2.57,3.65])$, and a diagnosis of pneumonia $[1.44(1.21,1.71)]$. Factors significantly associated with a lower risk included concurrent chronic obstructive pulmonary disease $[0.65(0.55,0.77)]$ and female sex $[0.67(0.57,0.79)]$. Conclusions Patients with IPF, particularly those receiving mechanical ventilation or intensive care, are at substantial risk of death or lung transplant during hospitalization or death during a readmission within 90 days.
\end{abstract}

Keywords Critical care $\cdot$ Hospitalization $\cdot$ Intensive care $\cdot$ Mechanical ventilation $\cdot$ Interstitial lung disease

Electronic supplementary material The online version of this article (https://doi.org/10.1007/s00408-019-00270-z) contains supplementary material, which is available to authorized users.

Michael T. Durheim

michael.durheim@duke.edu

Duke Clinical Research Institute, Durham, NC, USA

2 Duke University Medical Center, PO Box 102355, Durham, NC 27710, USA

3 Department of Respiratory Medicine, Oslo University Hospital - Rikshospitalet, Oslo, Norway

4 Premier Inc, Charlotte, NC, USA

5 Boehringer Ingelheim Pharmaceuticals, Inc, Ridgefield, CT, USA

6 Vital Statistics LLC, Chapel Hill, NC, USA

\section{Introduction}

Idiopathic pulmonary fibrosis (IPF) is a progressive fibrosing interstitial lung disease (ILD) characterized by loss of lung function, which occurs mainly in adults over the age of 60 years [1]. IPF has a poor prognosis, with a median survival from the time of diagnosis of approximately 4 years [2]. Hospital admissions are frequent among patients with IPF and are associated with high mortality [3-11], particularly in the case of acute exacerbations of the disease [12].

Diagnostic code-based algorithms have been applied to large administrative databases to conduct population-based studies on the incidence, prevalence and survival of patients with IPF, as well as the economic burden of this disease $[2,4,8,13-17]$. The use of refined algorithms has enabled identification of patients with IPF with a positive predictive value (PPV) of over 80\% [15]. Large administrative databases have also been used to characterize in-hospital mortality in US patients with IPF [4, 8], but previous studies 
have been restricted by age, a single-payer focus and the limited data collected on patient characteristics and in-hospital treatments.

In this study, we leveraged previously validated algorithms, and addressed limits to their generalizability, by using information from diagnostic codes and billing data to identify patients with IPF in the Premier Healthcare Database (PHD). The PHD is a nationally representative administrative dataset that includes over $20 \%$ of hospital discharges in the US, independent of payer, and provides patient-level data on hospital stays, including detailed information on hospital and patient characteristics, diagnostic testing, and treatments. We determined in-hospital mortality rates and the patient-, hospital-, and treatment-specific factors that were associated with in-hospital mortality, urgent lung transplant, or death during a readmission within 90 days of the index visit. In addition, we estimated the median length of hospital stay and identified factors associated with longer hospital stay or readmission.

\section{Methods}

\section{Study Design}

This was a retrospective cohort study of patients with a diagnosis of IPF who were hospitalized at 641 hospitals in the US. Patients were identified using an algorithm that included both diagnosis codes and billing data for chest computed tomography (CT) and/or lung biopsy. Validation of the coding algorithm was performed in a subset of patients through manual review of individual charts (see online supplementary material).

\section{Patients}

Patients with IPF aged $\geq 50$ years with a hospital discharge date between 1 October 2011 and 14 October 2014 were eligible for inclusion in the study. Following an approach used in previous studies [2, 15, 17], the diagnosis of IPF was based on a primary or secondary International Classification of Diseases Ninth Revision (ICD-9) diagnosis code of 516.3 or 516.31 and a billing code for chest CT and/or surgical lung biopsy $\leq 3$ years prior to the index hospitalization. The period studied was selected based on the introduction of the ICD-9 code of 516.31 for IPF (1 October 2011) and the FDA approval of nintedanib and pirfenidone as treatments for IPF (14 October 2014). Exclusion criteria were any ICD-9 codes for an alternative cause of ILD during the index hospitalization and an ICD-9 procedure code for lung transplant surgery $\leq 1$ day after admission. Patients who had lung transplant surgery within a day of admission were excluded, as death following transplant surgery is driven by different factors than death prior to transplant. Patients undergoing transplant $>1$ day after admission were included in the analysis, as they were admitted for a reason other than a planned transplant, and transplant surgery that occurs $>1$ day after admission likely reflects an urgent, rather than elective, procedure.

\section{Outcomes}

The primary outcome was a composite of in-hospital mortality: death during the index visit, lung transplant during the index visit but $>1$ day after admission, or death during a readmission within 90 days of the index visit. Secondary outcomes were length of stay in hospital and readmission to hospital within 90 days of the index visit due to any cause.

\section{Patient-, Hospital-, and Treatment-Related Characteristics}

Patient characteristics analyzed included sex, age, race, and primary payer. Hospital region (South, Midwest, West, North-East of the US), teaching status (academic, nonacademic), population served (urban, rural), and attending physician specialty (internal medicine/hospitalist, family medicine, pulmonary medicine, critical care/intensivist, other) were categorized. ICD-9 was used for identification of procedures or concurrent diagnoses in addition to billing descriptions (see online supplementary table). Mechanical ventilation was primarily identified based on invasive mechanical ventilation, but 36 records where it was unknown whether the ventilation was invasive or noninvasive were included. Surgical lung biopsy was identified based on Current Procedural Terminology (CPT) codes and billing descriptions. Chest $\mathrm{CT}$ was identified based on CPT codes. Intensive care unit (ICU) use was based on room and board billing. Antibiotics (intravenous [IV], oral), steroids (IV, oral), immunosuppressants (IV, oral), oral anticoagulants, and IV heparin were considered treatments of primary interest; data on use of these treatments were derived from billing descriptions.

\section{Statistical Analyses}

Logistic regression was used to determine associations between patient-, hospital-, and treatment-related characteristics and the primary outcome, as well as between these factors and readmission within 90 days of the index visit. Length of stay was modeled using negative binomial regression and estimates based on patient-, hospital-, and treatment-related factors were calculated. Models were built using bidirectional stepwise variable selection, and an alpha value of 0.01 was considered statistically significant for the purpose of covariate inclusion in the modeling 
Table 1 Characteristics of 6665 hospitalized patients with idiopathic pulmonary fibrosis identified from a representative US database

\begin{tabular}{ll}
\hline Age, years, median (interquartile range) & $75(67-82)$ \\
Male, $n(\%)$ & $3606(54.1)$ \\
Race, $n(\%)$ & \\
White & $5343(80.2)$ \\
Black & $453(6.8)$ \\
Other & $869(13.0)$ \\
Primary payer, $n(\%)$ & \\
Medicare & $5370(80.6)$ \\
Managed care & $583(8.7)$ \\
Medicaid & $312(4.7)$ \\
Commercial & $165(2.5)$ \\
Other & $235(3.5)$ \\
Hospital location-US region, $n(\%)$ & \\
South & $3198(48.0)$ \\
Midwest & $1562(23.4)$ \\
West & $1061(15.9)$ \\
Northeast & $844(12.7)$ \\
Attending physician specialty, $n(\%)$ & \\
Internal medicine/hospitalist & $4428(66.4)$ \\
Family medicine & $584(8.8)$ \\
Pulmonary medicine & $453(6.8)$ \\
Critical care/intensivist & $126(1.9)$ \\
Other & $1074(16.1)$ \\
Admitted to teaching hospital, $n(\%)$ & $2735(41.0)$ \\
Population served by hospital, $n(\%)$ & \\
Urban & $5850(87.8)$ \\
Rural & $815(12.2)$ \\
\hline
\end{tabular}

process. We conducted the analyses using a patient-level perspective, in which every patient was counted once, using their first visit during the study period as the index visit.

\section{Results}

\section{Patients}

The cohort consisted of 6665 hospitalized patients with IPF (Table 1). Median age was 75 years and $54.1 \%$ of patients were male. Comorbidities and medication use, particularly those related to respiratory and cardiovascular disease, were common (Fig. 1; Table 2). Notably, almost $79 \%$ of patients received antibiotics, and the majority received parenteral heparin, and/or oral or parenteral corticosteroids. Over a quarter $(28 \%)$ of patients received care in the ICU, with mechanical ventilation performed in $10 \%$ of patients. Almost $60 \%$ of patients received a chest

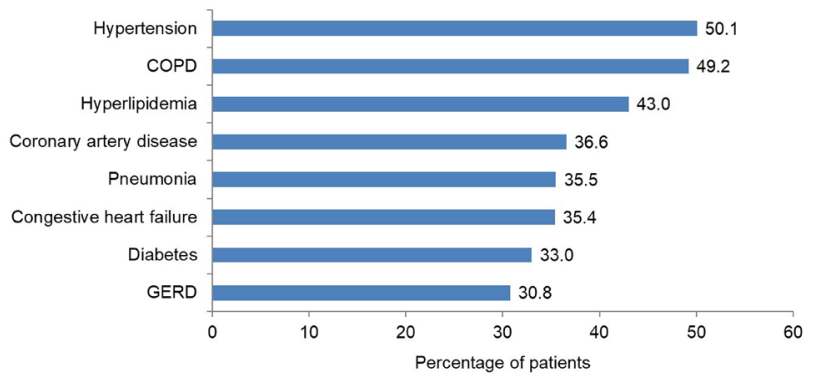

Fig. 1 Concurrent diagnoses among patients with idiopathic pulmonary fibrosis identified from a representative US database. Concurrent diagnoses reported in $>30 \%$ of patients are shown. COPD chronic obstructive pulmonary disease, GERD gastroesophageal reflux disease

Table 2 Interventions among 6665 hospitalized patients with idiopathic pulmonary fibrosis identified from a representative US database

Diagnostic tests

Chest HRCT

$3946(59.2)$

Echocardiogram

$749(11.2)$

Bronchoscopy

$440(6.6)$

Lung biopsy

$276(4.1)$

Medication use ${ }^{\mathrm{a}}$

Antibiotic

$5259(78.9)$

Parenteral heparin

$4549(68.3)$

Proton pump inhibitor

$4172(62.6)$

Diuretic

3909 (58.6)

Oral or parenteral corticosteroid

$3850(57.8)$

Opiate

$3235(48.5)$

Statin

3039 (45.6)

Aspirin

$2915(43.7)$

Oral anticoagulant

$1142(17.1)$

Mechanical ventilation

$664(10.0)$

Admission to ICU

$1869(28.0)$

Surgery

$208(3.1)$

${ }^{a}$ Medications utilized in $>5 \%$ of patients are shown. HRCT, high-resolution computed tomography; ICU, intensive care unit

HRCT, while $6.6 \%$ and $4.1 \%$ received bronchoscopy or lung biopsy, respectively.

\section{In-Hospital Mortality}

A total of 963 patients (14.4\%) met the primary outcome: 684 patients $(10.3 \%)$ died during the index visit, 267 patients $(4.0 \%)$ died during a readmission within 90 days, and 12 patients $(0.2 \%)$ underwent lung transplantation during the index visit but $>1$ day after admission. Factors significantly associated with a higher risk of the primary outcome included mechanical ventilation [odds ratio 


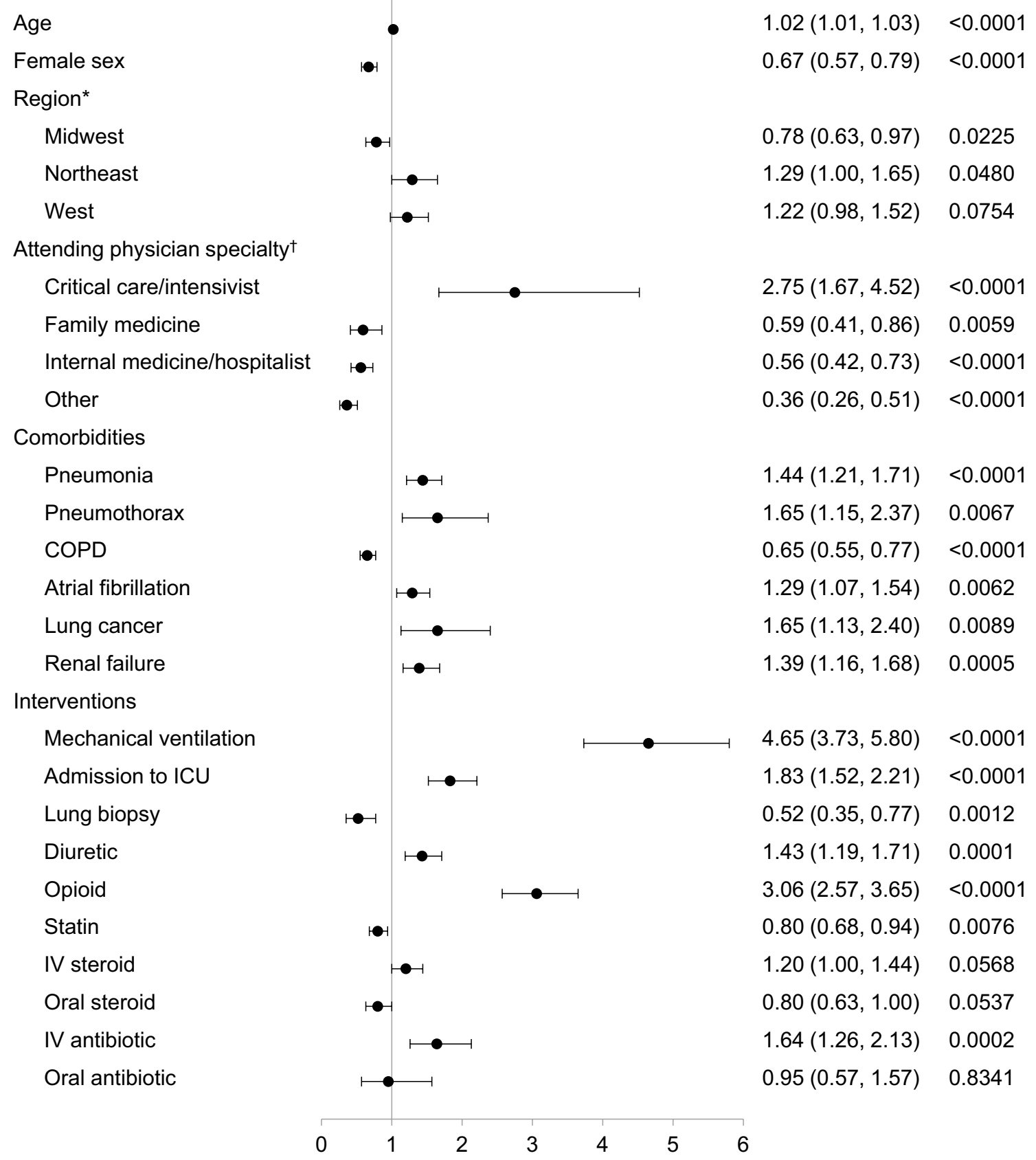

${ }^{*}$ Compared with South. ${ }^{\dagger}$ Compared with pulmonologist.

Fig. 2 Associations between patient-, hospital- and treatment-related factors and in-hospital mortality or lung transplantation in patients with idiopathic pulmonary fibrosis. $C O P D$ chronic obstructive pulmonary disease, $I C U$ intensive care unit, $I V$ intravenous

(OR) 4.65 (95\% CI 3.73, 5.80)], admission to the ICU [OR $1.83(95 \%$ CI $1.52,2.21)]$, attendance by a critical care physician [OR $2.75(95 \%$ CI $1.67,4.52)]$, treatment with opioids [OR $3.06(95 \%$ CI $2.57,3.65)$ ], and concurrent pneumonia [OR 1.44 (95\% CI 1.21, 1.71)] (Fig. 2). The primary outcome was met by 578 (30.9\%) of the 1869 patients admitted to ICU, $77(61.1 \%)$ of the 126 patients attended by a critical care physician, $366(55.1 \%)$ of the 664 patients who received mechanical ventilation, 733 (22.7\%) of the 3235 patients who received opioids and 485 (20.5\%) of the 2368 patients who had pneumonia. 
Factors significantly associated with a lower risk of the primary outcome included attendance by an internal medicine [OR $0.56(95 \%$ CI $0.42,0.73)$ ] or family medicine physician [OR 0.59 (95\% CI 0.41, 0.86)], concurrent COPD [OR 0.65 (95\% CI 0.55, 0.77)], and female sex [OR 0.67 (95\% CI 0.57, 0.79)] (Fig. 2).

\section{Length of Stay}

Median (interquartile range) length of stay in hospital was 5 (3-9) days: 8 (4-14) days for patients who died in hospital and 5 (3-8) days for patients who did not. Patients diagnosed with pneumonia were estimated to have a $15 \%$ longer hospital stay than those who were not, and patients diagnosed with pneumothorax were estimated to have a $49 \%$ longer hospital stay than those who were not (Table 3 ). Patients admitted to the ICU were estimated to have a $32 \%$ longer hospital stay than those who were not, while patients who received mechanical ventilation were estimated to have a $22 \%$ longer stay than those who did not. Patients undergoing bronchoscopy and lung biopsy were estimated to have $32 \%$ and $23 \%$ longer hospital stays, respectively, than those who did not.

\section{Readmission}

A total of 1990 patients $(29.9 \%)$ were readmitted to hospital within 90 days of the index visit, of whom 267 patients (4.0\% of the overall population; $13.4 \%$ of those readmitted) died during the readmission visit. Factors significantly associated with a higher risk of 90-day readmission included admission within 365 days prior to the index visit for any reason [OR 1.86 (95\% CI 1.65, 2.08)], a longer length of stay in the index visit [OR $1.02(95 \%$ CI 1.02, 1.03)], concurrent congestive heart failure [OR 1.30 (95\% CI 1.16, 1.46]), concurrent coronary artery disease [OR 1.23 (95\% CI 1.09, 1.38)], use of oral steroids [OR 1.28 (95\% CI 1.11, 1.48), and use of IV steroids [OR $1.16(1.02,1.33)]$ (Fig. 3).

\section{Discussion}

In this analysis of 6665 patients with IPF hospitalized across 641 US hospitals, approximately $14 \%$ of patients died during the index admission, underwent urgent lung transplant, or died during a readmission within 90 days. As the database used was not limited by patient age, payer, or hospital type, this estimate of in-hospital mortality is broadly representative of US patients with IPF. Similar rates of in-hospital mortality in patients with IPF have been reported in the US
Nationwide Inpatient Sample (14\%) [8, 18], US Healthcare Cost and Utilization Project Nationwide Readmissions Database (11\%) [19], the Spanish National Hospital Discharge Database (14\%) [20], and the French hospital discharge database (13\%) [7]. A higher rate (23\%) was reported in patients with IPF who were hospitalized between April 2010 and March 2013 in the nationwide Japanese database, likely due in part to the exclusion of some elective hospitalizations [9].

Mechanical ventilation was the most striking factor associated with the composite mortality outcome, with an almost five-fold increased odds for death. Consistent with data from the US Nationwide Inpatient Sample [21], more than half of the patients who underwent mechanical ventilation died during admission/readmission or underwent lung transplant. Admission to the ICU or attendance by a critical care physician (which usually occurs in an ICU) was also associated with a significantly increased risk of mortality. Comorbidities associated with an increased risk of mortality included pneumonia, pneumothorax, atrial fibrillation, lung cancer, and renal failure. Identifying prognostic factors, and quantifying the strength of their association with mortality, may assist patients, families, and clinicians in making decisions about their care, particularly regarding the potential benefits and risks of ICU care and mechanical ventilation.

Among treatments, opioids were most strongly associated with mortality, most likely reflecting the palliation of endstage disease. Other treatments associated with increased mortality included diuretics and IV antibiotics, consistent with the associations between renal failure and pneumonia and mortality. Oral or IV steroids were not associated with improved mortality, while statin use was associated with a slightly reduced risk.

Female patients had a lower risk of in-hospital mortality. The explanation for this finding is unknown. It may be that a greater proportion of female than male patients were assigned a diagnosis code for IPF during their hospitalization when in fact they had connective tissue disease-associated ILD, which is associated with lower mortality than IPF $[22,23]$. However, the validated approach used to identify IPF, and the lack of a difference in the PPV of the algorithm between males and females, make this a less likely explanation. Several retrospective cohort studies have shown that mortality is higher in male patients with IPF [10, 24, 25]. A study that used a regression model to identify predictors of mortality in patients with ILD admitted to an ICU for respiratory failure found higher mortality in males [23]. In a mouse model of bleomycin-induced lung fibrosis, males develop increased inflammatory cytokines, collagen deposition, neutrophilic alveolitis, and have higher mortality than 
Table 3 Estimated lengths of stay in hospital among patients with idiopathic pulmonary fibrosis based on patient-, hospital-, and treatment-related factors

\begin{tabular}{|c|c|c|c|}
\hline Parameter & Coefficient estimate (SE) & $\begin{array}{l}\text { Exponential } \\
\text { estimate }^{\mathrm{a}}\end{array}$ & $p$ value \\
\hline \multicolumn{4}{|l|}{ Insurance (vs medicare) } \\
\hline Medicaid & $0.09(0.04)$ & 1.09 & 0.0126 \\
\hline Managed care & $-0.05(0.03)$ & 0.96 & 0.0955 \\
\hline Commercial & $-0.06(0.05)$ & 0.94 & 0.2095 \\
\hline Other & $-0.07(0.04)$ & 0.93 & 0.0839 \\
\hline \multicolumn{4}{|l|}{ Region (vs South) } \\
\hline Northeast & $0.03(0.03)$ & 1.03 & 0.3201 \\
\hline West & $-0.08(0.02)$ & 0.93 & 0.0005 \\
\hline Midwest & $-0.12(0.02)$ & 0.89 & $<0.0001$ \\
\hline Rural hospital (vs urban) & $-0.09(0.03)$ & 0.91 & 0.0001 \\
\hline Teaching hospital (vs non-teaching) & $0.08(0.02)$ & 1.08 & $<0.0001$ \\
\hline \multicolumn{4}{|c|}{ Attending physician specialty (vs pulmonologist) } \\
\hline Family medicine & $0.06(0.04)$ & 1.06 & 0.1143 \\
\hline Other & $0.05(0.04)$ & 1.05 & 0.1350 \\
\hline Internal medicine/hospitalist & $-0.02(0.03)$ & 0.98 & 0.5595 \\
\hline Critical care/intensivist & $-0.29(0.06)$ & 0.75 & $<0.0001$ \\
\hline \multicolumn{4}{|l|}{ Concurrent diagnoses } \\
\hline Pneumothorax & $0.40(0.04)$ & 1.49 & $<0.0001$ \\
\hline Malnutrition & $0.32(0.03)$ & 1.37 & $<0.0001$ \\
\hline Diverticulosis & $0.17(0.04)$ & 1.19 & $<0.0001$ \\
\hline Renal failure & $0.17(0.02)$ & 1.18 & $<0.0001$ \\
\hline Pneumonia & $0.14(0.02)$ & 1.15 & $<0.0001$ \\
\hline Cerebrovascular disease & $0.14(0.03)$ & 1.15 & $<0.0001$ \\
\hline Acute heart failure & $0.07(0.02)$ & 1.07 & 0.0029 \\
\hline \multicolumn{4}{|l|}{ Interventions } \\
\hline Mycophenolate & $0.34(0.06)$ & 1.40 & $<0.0001$ \\
\hline Admission to ICU & $0.28(0.02)$ & 1.32 & $<0.0001$ \\
\hline Bronchoscopy & $0.28(0.03)$ & 1.32 & $<0.0001$ \\
\hline Diuretic & $0.25(0.02)$ & 1.29 & $<0.0001$ \\
\hline Intravenous antibiotic & $0.25(0.02)$ & 1.28 & $<0.0001$ \\
\hline Lung biopsy & $0.20(0.04)$ & 1.23 & $<0.0001$ \\
\hline Mechanical ventilation & $0.20(0.03)$ & 1.22 & $<0.0001$ \\
\hline Oral antibiotic & $0.20(0.04)$ & 1.22 & $<0.0001$ \\
\hline Phosphodiesterase type 5 inhibitor & $0.19(0.05)$ & 1.21 & $<0.0001$ \\
\hline Opioid & $0.18(0.02)$ & 1.20 & $<0.0001$ \\
\hline Surgery & $0.18(0.04)$ & 1.20 & $<0.0001$ \\
\hline Anticoagulant & $0.14(0.02)$ & 1.15 & $<0.0001$ \\
\hline Chest HRCT & $0.14(0.02)$ & 1.15 & $<0.0001$ \\
\hline Intravenous steroid & $0.14(0.02)$ & 1.15 & $<0.0001$ \\
\hline Oral steroid & $0.11(0.02)$ & 1.12 & $<0.0001$ \\
\hline Proton pump inhibitor & $0.11(0.02)$ & 1.11 & $<0.0001$ \\
\hline Heparin & $0.10(0.02)$ & 1.10 & $<0.0001$ \\
\hline Echocardiogram & $0.09(0.02)$ & 1.09 & 0.0004 \\
\hline Prior admission (within past 365 days) & $0.08(0.02)$ & 1.08 & $<0.0001$ \\
\hline
\end{tabular}

$H R C T$ high-resolution computed tomography, ICU intensive care unit

${ }^{a}$ Estimated length of stay relative to the reference group 


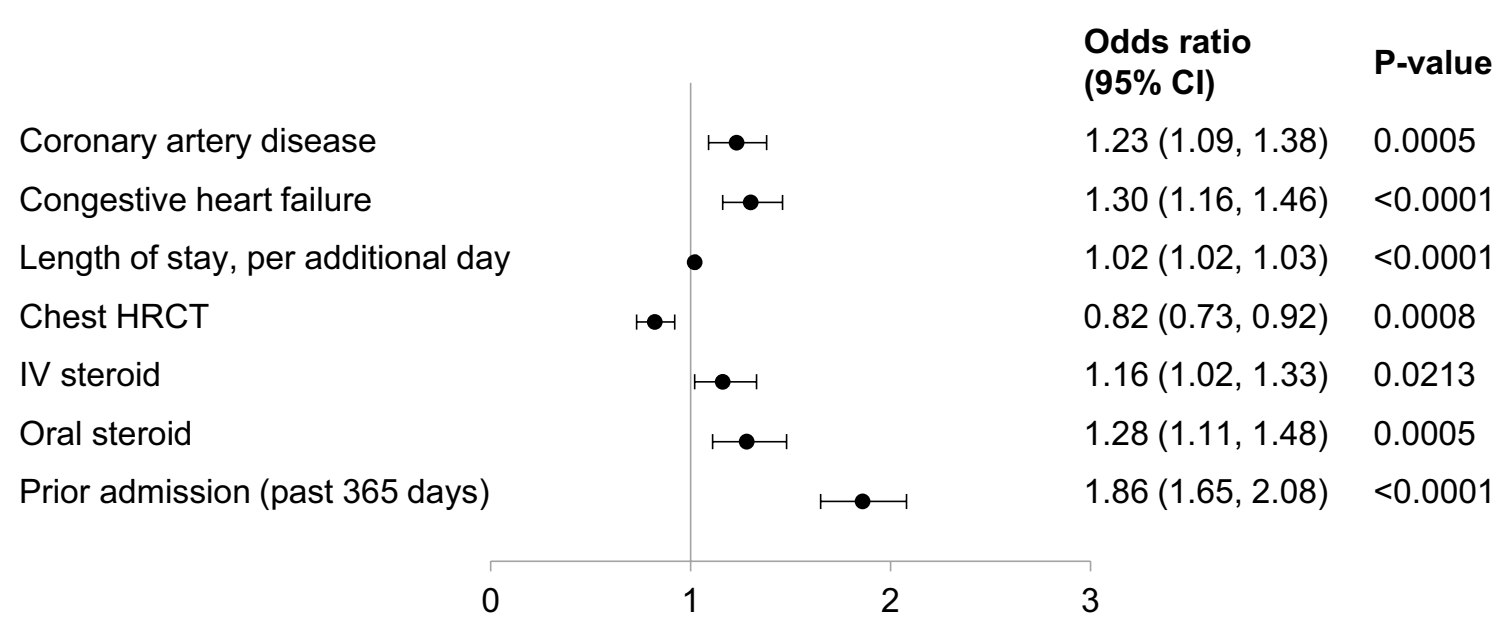

Fig. 3 Associations between patient-, hospital- and treatment-related factors and 90-day readmission in patients with idiopathic pulmonary fibrosis. HRCT high-resolution computed tomography, $I V$ intravenous

females, suggesting that there may be differences between genders in processes that drive progression of fibrosis [26].

Interestingly, in our study, patients with concurrent COPD had a lower risk of in-hospital mortality. This might have been because in some of these patients, it was worsening of COPD, rather than IPF, that led to the hospitalization, and worsening of COPD is associated with lower mortality. Also of interest were some factors that were not associated with mortality in our study, for example, insurance provider, region, and academic status of the hospital.

The median length of hospital stay was 5 days. This is shorter than the lengths of stay reported in previous realworld studies and clinical trials, which have ranged from 7 to 10.2 days $[3,7,8,20,27]$, likely reflecting differing patient populations and healthcare systems. Length of stay was $32 \%$ longer in patients receiving intensive care. Consistent with previous observations [21], LOS was $22 \%$ longer among patients receiving mechanical ventilation. These interventions come at considerable economic cost, with a previous US study estimating an increase of over $\$ 35,000$ per stay associated with invasive mechanical ventilation and over $\$ 5000$ per stay associated with non-invasive mechanical ventilation [21]. Patients who underwent bronchoscopy or surgical lung biopsy also had longer hospital stays. The reasons for this were not investigated in our study, but may be related to complications such as pneumothorax.

Almost a third of the hospitalized patients with IPF in our analysis were readmitted to a hospital within 90 days. The strongest predictor of readmission was admission within the previous year. These data suggest that there is a subset of patients with IPF who experience frequent hospital admissions; further studies to characterize these patients would be valuable.
Our analyses have several limitations. Our study was limited to the US, which has a different healthcare system to other countries. It is possible that we over- or under-estimated the IPF cohort in our database based on our coding approach; however, the PPV of our algorithm was consistent with previous studies [15]. Using diagnoses of IPF, as well as concurrent conditions, based on administrative data has inherent limitations. For example, it is not possible to determine the extent to which diagnoses of pneumonia reflect concurrent lung infections as opposed to acute exacerbations of IPF. Some factors associated with mortality in patients with IPF (e.g. lung function, use of supplementary oxygen) could not be investigated in our analyses. Assessment of readmissions was based only on readmissions to the same hospital, resulting in underestimation of readmission rates and probably also mortality [28]. Deaths outside of hospital were not captured.

Our study covered a period prior to the approval of pirfenidone and nintedanib as treatments for IPF. The use of antifibrotic therapies reduces the risk of acute worsenings of IPF [29-31] and there is increasing evidence that they improve survival [32-37]. Our study provides a basis for future studies looking at the effects of antifibrotic therapies on the outcomes of hospitalizations in a contemporary IPF cohort.

In conclusion, our findings, based on a representative national cohort of hospitalized patients in the US, provide clinically relevant insights into the factors associated with in-hospital mortality in patients with IPF. Patients with IPF, particularly those receiving mechanical ventilation or intensive care, or diagnosed with pneumonia, are at substantial risk of death during hospitalization, lung transplant during admission, or death during a readmission within 90 days. Female patients and those with comorbid COPD appear to 
be at lower risk of in-hospital mortality. Patients with IPF spend a median of 5 days in hospital, with ICU admission, mechanical ventilation, bronchoscopy, and surgical lung biopsy associated with a longer duration of stay.

Acknowledgements This study was funded by Boehringer Ingelheim Pharmaceuticals, Inc as a collaboration with Duke Clinical Research Institute and Premier, Inc. The authors thank Ann Von Worley, RN, BSHS, CCRP, of LCF Research, Albuquerque, New Mexico, USA, who assisted in conducting the chart reviews and provided the protocol for the medical record abstraction process. Writing support was provided by Julie Fleming and Wendy Morris of FleishmanHillard Fishburn, London, UK which was contracted and funded by Boehringer Ingelheim Pharmaceuticals, Inc. for these services. The authors meet criteria for authorship as recommended by the International Committee of Medical Journal Editors (ICMJE), received no direct compensation for the development of the manuscript, were fully responsible for all content and editorial decisions, were involved at all stages of development, and have approved the final version. Boehringer Ingelheim was given the opportunity to review the manuscript for medical and scientific accuracy as well as intellectual property considerations.

\section{Compliance with Ethical Standards}

Conflict of interest MTD, OM, BRS, and SMP are faculty members in the Duke Clinical Research Institute (DCRI), which received funding from Boehringer Ingelheim Pharmaceuticals, Inc (BIPI) to coordinate this project. MTD also reports grants and personal fees from Boehringer Ingelheim, and personal fees from Roche. JL was an employee of DCRI at the time that this research was conducted. JJ, DB, and SBR are employees of Premier, Inc which received funding from BIPI for work related to this project. SB, TL, and CSC are employees of BIPI

Open Access This article is distributed under the terms of the Creative Commons Attribution 4.0 International License (http://creativeco mmons.org/licenses/by/4.0/), which permits unrestricted use, distribution, and reproduction in any medium, provided you give appropriate credit to the original author(s) and the source, provide a link to the Creative Commons license, and indicate if changes were made.

\section{References}

1. Raghu G, Remy-Jardin M, Myers JL, Richeldi L, Ryerson CJ, Lederer DJ, Behr J, Cottin V, Danoff SK, Morell F, Flaherty KR, Wells A, Martinez FJ, Azuma A, Bice TJ, Bouros D, Brown KK, Collard HR, Duggal A, Galvin L, Inoue Y, Jenkins RG, Johkoh T, Kazerooni EA, Kitaichi M, Knight SL, Mansour G, Nicholson AG, Pipavath SNJ, Buendía-Roldán I, Selman M, Travis WD, Walsh S, Wilson KC; American Thoracic Society, European Respiratory Society, Japanese Respiratory Society, and Latin American Thoracic Society (2018) Diagnosis of idiopathic pulmonary fibrosis. An official ATS/ERS/JRS/ALAT clinical practice guideline. Am J Respir Crit Care Med 198:e44-e68

2. Raghu G, Chen SY, Yeh WS, Maroni B, Li Q, Lee YC, Collard HR (2014) Idiopathic pulmonary fibrosis in US Medicare beneficiaries aged 65 years and older: incidence, prevalence, and survival, 2001-2011. Lancet Respir Med 2:566-572

3. Brown AW, Fischer CP, Shlobin OA, Buhr RG, Ahmad S, Weir NA, Nathan SD (2015) Outcomes after hospitalization in idiopathic pulmonary fibrosis: a cohort study. Chest 147:173-179
4. Collard HR, Chen SY, Yeh WS, Li Q, Lee YC, Wang A, Raghu G (2015) Health care utilization and costs of idiopathic pulmonary fibrosis in U.S. Medicare beneficiaries aged 65 years and older. Ann Am Thorac Soc 12:981-987

5. Durheim M, Collard HR, Roberts RS, Brown KK, Flaherty KR, King TE Jr, Palmer SM, Raghu G, Snyder LD, Anstrom KJ, Martinez FJ (2015) Association of hospital admission and forced vital capacity endpoints with survival in patients with idiopathic pulmonary fibrosis: analysis of a pooled cohort from three clinical trials. Lancet Respir Med 3:388-396

6. Raimundo K, Chang E, Broder MS, Alexander K, Zazzali J, Swigris JJ (2016) Clinical and economic burden of idiopathic pulmonary fibrosis: a retrospective cohort study. BMC Pulm Med 16:2

7. Cottin V, Schmidt A, Catella L, Porte F, Fernandez-Montoya C, Le Lay K, Bénard S (2017) Burden of idiopathic pulmonary fibrosis progression: a 5-year longitudinal follow-up study. PLoS ONE 12:e0166462

8. Mooney JJ, Raimundo K, Chang E, Broder MS (2017) Hospital cost and length of stay in idiopathic pulmonary fibrosis. J Med Econ 20:518-524

9. Oda K, Yatera K, Fujino Y, Kido T, Hanaka T, Sennari K, Fushimi K, Matsuda S, Mukae H (2018) Respiratory comorbidities and risk of mortality in hospitalized patients with idiopathic pulmonary fibrosis. Respir Investig 56:64-71

10. Pedraza-Serrano F, Jiménez-García R, López-de-Andrés A, Hernández-Barrera V, Esteban-Hernández J, Sánchez-Muñoz G, Puente-Maestu L, de-Miguel-Díez J (2018) Comorbidities and risk of mortality among hospitalized patients with idiopathic pulmonary fibrosis in Spain from 2002 to 2014. Respir Med 138:137-143

11. Fan Y, Bender S, Conoscenti C, Knight JD, Davidson-Ray L, Cowper PA, Palmer SM, de Andrade JA (2018) Hospital-based resource use and costs amongst patients with idiopathic pulmonary fibrosis enrolled in the IPF-PRO Registry. Abstract presented at AMCP Nexus meeting, October 22-25 2018, Orlando

12. Collard HR, Ryerson CJ, Corte TJ, Jenkins G, Kondoh Y, Lederer DJ, Lee JS, Maher TM, Wells AU, Antoniou KM, Behr J, Brown KK, Cottin V, Flaherty KR, Fukuoka J, Hansell DM, Johkoh T, Kaminski N, Kim DS, Kolb M, Lynch DA, Myers JL, Raghu G, Richeldi L, Taniguchi H, Martinez FJ (2016) Acute exacerbation of idiopathic pulmonary fibrosis. An international working group report. Am J Respir Crit Care Med 194:265-275

13. Raghu G, Weycker D, Edelsberg J, Bradford WZ, Oster G (2006) Incidence and prevalence of idiopathic pulmonary fibrosis. Am J Respir Crit Care Med 174:810-816

14. Fernández Pérez ER, Daniels CE, Schroeder DR, St Sauver J, Hartman TE, Bartholmai BJ, Yi ES, Ryu JH (2010) Incidence, prevalence, and clinical course of idiopathic pulmonary fibrosis: a population-based study. Chest 137:129-137

15. Esposito DB, Lanes S, Donneyong M, Holick CN, Lasky JA, Lederer D, Nathan SD, O'Quinn S, Parker J, Tran TN (2015) Idiopathic pulmonary fibrosis in United States automated claims. Incidence, prevalence, and algorithm validation. Am J Respir Crit Care Med 192:1200-1207

16. Raghu G, Chen SY, Hou Q, Yeh WS, Collard HR (2016) Incidence and prevalence of idiopathic pulmonary fibrosis in US adults 18-64 years old. Eur Respir J 48:179-186

17. Ley B, Urbania T, Husson G, Vittinghoff E, Brush DR, Eisner MD, Iribarren C, Collard HR (2017) Code-based diagnostic algorithms for idiopathic pulmonary fibrosis. case validation and improvement. Ann Am Thorac Soc 14:880-887

18. Raimundo K, Chang E, Broder M, Zazzali J (2015) Inhospital length of stay and mortality for patients with idiopathic pulmonary fibrosis (IPF) in the US. Chest 148(4_MeetingAbstracts):402A 
19. Ghobrial M, Chowdhury A, Zein JG (2018) Predictors of 30-day readmission in patients with idiopathic pulmonary fibrosis. Abstract presented at the American Thoracic Society International Conference, San Diego, CA, USA, 18-23 May 2018

20. Pedraza-Serrano F, López de Andrés A, Jiménez-García R, Jiménez-Trujillo I, Hernández-Barrera V, Sánchez-Muñoz G, Puente-Maestu L, de Miguel-Díez J (2017) Retrospective observational study of trends in hospital admissions for idiopathic pulmonary fibrosis in Spain (2004-2013) using administrative data. BMJ Open 7:e013156

21. Mooney JJ, Raimundo K, Chang E, Broder MS (2017) Mechanical ventilation in idiopathic pulmonary fibrosis: a nationwide analysis of ventilator use, outcomes, and resource burden. BMC Pulm Med 17:84

22. Oldham JM, Adegunsoye A, Valenzi E, Lee C, Witt L, Chen L, Husain AN, Montner S, Chung JH, Cottin V, Fischer A, Noth I, Vij R, Strek ME (2016) Characterisation of patients with interstitial pneumonia with autoimmune features. Eur Respir J 47:1767-1775

23. Gannon WD, Lederer DJ, Biscotti M, Javaid A, Patel NM, Brodie D, Bacchetta M, Baldwin MR (2018) Outcomes and mortality prediction model of critically ill adults with acute respiratory failure and interstitial lung disease. Chest 153:1387-1395

24. Han MK, Murray S, Fell CD, Flaherty KR, Toews GB, Myers J, Colby TV, Travis WD, Kazerooni EA, Gross BH, Martinez FJ (2008) Sex differences in physiological progression of idiopathic pulmonary fibrosis. Eur Respir J 31:1183-1188

25. Mooney J, Raimundo K, Chang E, Broder MS (2016) Association between clinical characteristics and in-hospital mortality in patients with idiopathic pulmonary fibrosis. Am J Respir Crit Care Med 193:A6225

26. Redente EF, Jacobsen KM, Solomon JJ, Lara AR, Faubel S, Keith RC, Henson PM, Downey GP, Riches DW (2011) Age and sex dimorphisms contribute to the severity of bleomycininduced lung injury and fibrosis. Am J Physiol Lung Cell Mol Physiol 301:L510-518

27. Diamantopoulos A, Maher TM, Schoof N, Esser D, LeReun C (2018) Influence of idiopathic pulmonary fibrosis progression on healthcare resource use. Pharmacoecon Open. https://doi. org/10.1007/s41669-018-0085-0

28. Staples JA, Thiruchelvam D, Redelmeier DA (2014) Site of hospital readmission and mortality: a population-based retrospective cohort study. CMAJ Open 2:E77-E85

29. Richeldi L, du Bois RM, Raghu G, Azuma A, Brown KK, Costabel U, Cottin V, Flaherty KR, Hansell DM, Inoue Y, Kim DS, Kolb M, Nicholson AG, Noble PW, Selman M, Taniguchi H, Brun M, Le Maulf F, Girard M, Stowasser S, Schlenker-Herceg R, Disse B, Collard HR, INPULSIS trial investigators (2014) Efficacy and safety of nintedanib in idiopathic pulmonary fibrosis. N Engl J Med 370:2071-2082
30. Collard HR, Richeldi L, Kim DS, Taniguchi H, Tschoepe I, Luisetti M, Roman J, Tino G, Schlenker-Herceg R, Hallmann C, du Bois RM (2017) Acute exacerbations in the INPULSIS trials of nintedanib in idiopathic pulmonary fibrosis. Eur Respir J. https:// doi.org/10.1183/13993003.01339-2016

31. Ley B, Swigris J, Day BM, Stauffer JL, Raimundo K, Chou W, Collard HR (2017) Pirfenidone reduces respiratory-related hospitalizations in idiopathic pulmonary fibrosis. Am J Respir Crit Care Med 196:756-761

32. Richeldi L, Cottin V, du Bois RM, Selman M, Kimura T, Bailes Z, Schlenker-Herceg R, Stowasser S, Brown KK (2016) Nintedanib in patients with idiopathic pulmonary fibrosis: combined evidence from the TOMORROW and INPULSIS trials. Respir Med 113:74-79

33. Noble PW, Albera C, Bradford WZ, Costabel U, du Bois RM, Fagan EA, Fishman RS, Glaspole I, Glassberg MK, Lancaster L, Lederer DJ, Leff JA, Nathan SD, Pereira CA, Swigris JJ, Valeyre D, King TE Jr (2016) Pirfenidone for idiopathic pulmonary fibrosis: analysis of pooled data from three multinational phase 3 trials. Eur Respir J 47:243-253

34. Fisher M, Nathan SD, Hill C, Marshall J, Dejonckheere F, Thuresson PO, Maher TM (2017) Predicting life expectancy for pirfenidone in idiopathic pulmonary fibrosis. J Manag Care Spec Pharm 23:S17-S24

35. Lancaster L, Crestani B, Hernandez P, Inoue Y, Wachtlin D, Loaiza L, Quaresma M, Stowasser S, Richeldi L (2019) Safety and survival data in patients with idiopathic pulmonary fibrosis treated with nintedanib: pooled data from six clinical trials. BMJ Open Respir Res 6:e000397

36. Guenther A, Krauss E, Tello S, Wagner J, Paul B, Kuhn S, Maurer O, Heinemann S, Costabel U, Barbero MAN, Müller V, Bonniaud P, Vancheri C, Wells A, Vasakova M, Pesci A, Sofia M, Klepetko W, Seeger W, Drakopanagiotakis F, Crestani B (2018) The European IPF registry (eurIPFreg): baseline characteristics and survival of patients with idiopathic pulmonary fibrosis. Respir Res 19:141

37. Zurkova M, Kriegova E, Kolek V, Lostakova V, Sterclova M, Bartos V, Doubkova M, Binkova I, Svoboda M, Strenkova J, Janotova M, Plackova M, Lacina L, Rihak V, Petrik F, Lisa P, Bittenglova R, Tyl R, Ondrejka G, Suldova H, Lnenicka J, Psikalova J, Snizek T, Homolka J, Kralova R, Kervitzer J, Vasakova M, ILD section, IPF registry (2019) Effect of pirfenidone on lung function decline and survival: 5-yr experience from a real-life IPF cohort from the Czech EMPIRE registry. Respir Res 20:16

Publisher's Note Springer Nature remains neutral with regard to jurisdictional claims in published maps and institutional affiliations. 